\section{Bisphosphonates reduce the risk of knee replacement: we need more analyses!}

With great interest, we read the recent article by Neogi et al entitled, 'Effect of bisphosphonates on knee replacement (KR) surgery'. ${ }^{1}$ In the study, the authors concluded that in this population-based cohort of older women with incident knee osteoarthritis (OA), those with incident bisphosphonate users had lower risk of KR than non-users of bisphosphonates, which was further supported by another large cohort study. ${ }^{2}$ The strengths of this study include a propensity score-matched cohort design, Cox proportional hazards regression to control for potential confounders and sensitivity analyses focused on residual confounding. Meanwhile, the authors acknowledged the limitations of their work. We applaud and congratulate their important work for clinical practice. However, several important points should be further discussed.

Generally, determinants of patient preferences for KR are OA severity, the level of knee pain, disability, and the weakness of quality of life, and more importantly, their willingness and access to KR. In the current study, authors tended to agree that reduced risk of KR has resulted from weakened OA progression after bisphosphonates use. However, recent high-level evidence indicated that bisphosphonates neither provide pain relief and function improvement nor radiographic progression in knee OA. ${ }^{34}$ Therefore, we wonder that bisphosphonates may affect the willingness and access to KR of patients with OA, thus reducing the risk of KR. Actually, many clinical and sociocultural factors, such as racial differences (African Americans and whites), social support and an educational intervention included a decision aid, have vital important influence on patient preferences for KR..$^{5-7}$ More importantly, a recent study revealed that patient preferences for KR were strongly associated with knee pain severity in patients with OA with health insurance, but their inverse relationship disappeared in patients without health insurance. ${ }^{8}$ Also, another study suggested that despite worse baseline knee pain and function, black participants had much lower adjusted risk of having total KR (TKR) than white participants. ${ }^{9}$ Thus, these indicated that sociocultural factors, but not OA severity, may have more significant influence on the willingness and access to KR. However, Neogi and colleagues seemed to ignore these important sociocultural factors in Cox proportional hazards regression, propensity score model and sensitivity analyses. We strongly recommend additional analyses based on aforementioned risk factors, which may further increase the robustness and credibility of the current study.

Additionally, the authors assessed the influence of bisphosphonates use on the risk of KR in patients with OA. However, there were no any data involving the baseline characteristics of $\mathrm{OA}$ severity, the level of knee pain, disability and the weakness of quality of life between both cohorts. Moreover, the influence of the dose, route, time point or measuring instrument of bisphosphonates administration on the risk of KR was unclear, so further subgroups should be warranted. Meanwhile, the primary outcome (the risk of KR) may be involved in many similar terms, such as TKR, revision KR, hemi-KR or KR in both knees. As with us, some readers may be confused about the notion. Therefore, the primary outcome should be clearly defined.

To sum up, we respect the great work done by the authors, but the study should be interpreted with the aforementioned limitations and further analyses should be performed.

\section{Hui-Zi Li, Xiang-He Xu, Hua-Ding Lu}

Department of Orthopaedics, Fifth Affiliated Hospital of Sun Yat-sen University, Zhuhai, China

Correspondence to Professor Hua-Ding Lu, Department of Orthopaedics, Fifth Affiliated Hospital of Sun Yat-sen University, Zhuhai, China; johnniehuading@163.com

Funding The study was funded by the national natural science foundation of China (No. 81772384; 81572174)

Competing interests None declared.

Patient consent Obtained.

Provenance and peer review Not commissioned; internally peer reviewed.

(c) Article author(s) (or their employer(s) unless otherwise stated in the text of the article) 2019. All rights reserved. No commercial use is permitted unless otherwise expressly granted.

\section{Check for updates}

To cite Li H-Z, Xu X-H, Lu H-D. Ann Rheum Dis 2019;78:e15.

Received 19 January 2018

Accepted 22 January 2018

Published Online First 2 February 2018

\section{S Linked}

- http://dx.doi.org/10.1136/annrheumdis-2018-213094

Ann Rheum Dis 2019;78:e15. doi:10.1136/annrheumdis-2018-213052

\section{REFERENCES}

1 Neogi T, Li S, Peloquin C, et al. Effect of bisphosphonates on knee replacement surgery. Ann Rheum Dis 2018;77:92-7.

2 Fu SH, Wang CY, Yang RS, et al. Bisphosphonate use and the risk of undergoing total knee arthroplasty in osteoporotic patients with osteoarthritis: a nationwide cohort study in taiwan. J Bone Joint Surg Am 2017;99:938-46.

3 Laslett LL, Kingsbury SR, Hensor EM, et al. Effect of bisphosphonate use in patients with symptomatic and radiographic knee osteoarthritis: data from the Osteoarthritis Initiative. Ann Rheum Dis 2014;73:824-30.

4 Vaysbrot EE, Osani MC, Musetti MC, et al. Are bisphosphonates efficacious in knee osteoarthritis? A meta-analysis of randomized controlled trials. Osteoarthritis Cartilage 2017. 10.1016/j.joca.2017.11.013. [Epub ahead of print 6 Dec 2016].

5 Zhang W, Lyman S, Boutin-Foster C, et al. Racial and ethnic disparities in utilization rate, hospital volume, and perioperative outcomes after total knee arthroplasty. J Bone Joint Surg Am 2016;98:1243-52.

6 Ibrahim SA, Blum M, Lee GC, et al. Effect of a decision aid on access to total knee replacement for black patients with osteoarthritis of the knee: a randomized clinical trial. JAMA Surg 2017;152:e164225.

7 Weng HH, Kaplan RM, Boscardin WJ, et al. Development of a decision aid to address racial disparities in utilization of knee replacement surgery. Arthritis Rheum 2007;57:568-75.

8 Vina ER, Ran D, Ashbeck EL, et al. Relationship between knee pain and patient preferences for joint replacement: health care access matters. Arthritis Care Res 2017;69:95-103.

9 MacFarlane LA, Kim E, Cook NR, et al. Racial variation in total knee replacement in a diverse nationwide clinical trial. J Clin Rheumatol 2018;24:1-5. 